\title{
Einige Bemerkungen zu Bolbodimyia bicolor Big.
}

Von V. v. Röder in Hoym (Anhalt).

Herr J. B i g o t beschreibt in der Wiener Entomologischen Zeitung, Jahrg. 1892, auf pag. 162 Bolbodimyia bicolor sibi, eine neue Tabanidenart, welche ich aus Merida in Venezuela besitze; ich kann somit der von Herrn Bigot gegebenen Beschreibung Einiges hinzufügen.

Die Bemerkung: „alis nigro-tinctis, externe obscurioribus, apice macula rotundata lata albida " passt nicht recht auf mein Exemplar; man muss von demselben sagen: „macula albida, margine interno, recta".

Die von Herrn Bigot gebrauchte Bezeichnung „alarum vena quarta longitudinali ( Rondani)" bezieht sich auf die dritte Längsader nach Schiner.

Ferner wäre zu ergänzen: Pedibus nigris, tibiis valde compressis et dilatatis, sed tibiis posterioribus nigrociliatis, non ealcaratis.

Was die Stellung der Gattung Bolbodimyia Big. zu den anderen Tabanidengattungen betrifft, so ist Bolbodimyia am nächsten der Gattung Selasoma Mcq. verwandt.

Selasoma tibialis Wied. (Mcq. Dipt. Exot. T. I, 2. Part., pag. 197, 188) besitzt an der oberen Zinke der dritten Längsader einen rücklaufenden Aderanhang. Sämmtliche Schienen sind verdickt, gebogen und aussen gewimpert. Das erste Fühlerglied ist etwas verdickt, aber schwächer als das dritte, welches sehr stark ist. Die Flügel sind bis über die Hälfte bräunlichschwarz, mit sehr kleinem, glashellem Punkt an der Wurzel; ein grösserer, fast viereckiger Punkt und darüber eine kleine Strieme, nahe am Aussenrande gelegen, sind glashell. Die Vorderrandader ist von der bräunlichschwarzen Zeichnung an bis an das Ende schön goldgelb. - Aus Brasilien. 


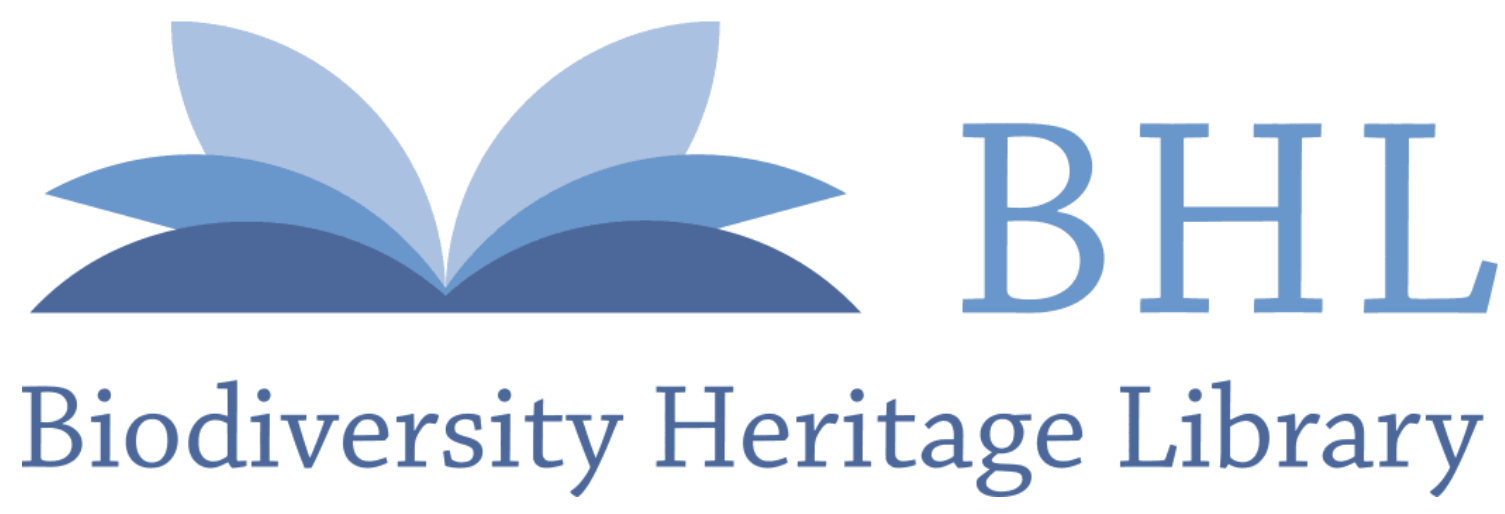

Röder, Victor von. 1892. "Einige Bemerkungen zu Bolbodimyia bicolor BIG." Wiener entomologische Zeitung 11, 237. https://doi.org/10.5962/bhl.part.27719.

View This Item Online: $\underline{\text { https://www.biodiversitylibrary.org/item/44096 }}$

DOI: https://doi.org/10.5962/bhl.part.27719

Permalink: https://www.biodiversitylibrary.org/partpdf/27719

\section{Holding Institution}

Smithsonian Libraries

\section{Sponsored by}

Smithsonian

\section{Copyright \& Reuse}

Copyright Status: NOT_IN_COPYRIGHT

This document was created from content at the Biodiversity Heritage Library, the world's largest open access digital library for biodiversity literature and archives. Visit BHL at https://www.biodiversitylibrary.org. 